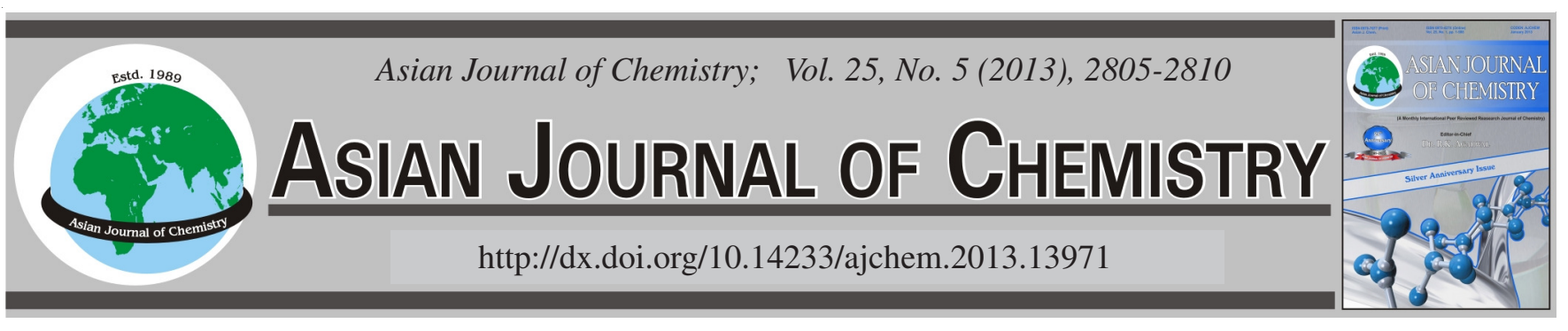

\title{
Stress-Softening and Interaction in Polydimethylsiloxane/Nano-Calcium Carbonate Networks
}

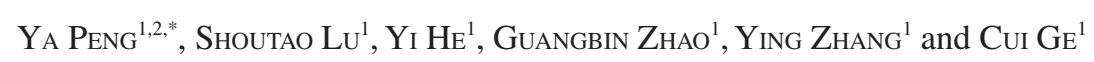

${ }^{1}$ School of Material Science and Engineering, Xihua University, Chengdu 610039, Sichuan Province, P.R. China

${ }^{2}$ Key Laboratory of Advanced Technologies of Materials (Ministry of Education), School of Materials Science and Engineering, Southwest Jiaotong University, Chengdu 610039, Sichuan Province, P.R. China

*Corresponding author: Fax: +86 28 87720514; Tel: +86 28 87726501; E-mail: pengyar@163.com; b897@163.com

\begin{abstract}
In this study, stress-softening and interaction in polydimethylsiloxane and nano-calcium carbonate was invested to understand the mechanism of reinforcement. The stress-softening found in both unfilled and filled polydimethylsiloxane was more prominent in filled polydimethylsiloxane, particularly for samples with high filler content. The interaction between polydimethylsiloxane and nano-calcium carbonate was verified by swelling experiment, cross-linking density measurement, dynamic laser light scattering and IR experiment. The results demonstrate that the interaction can be attributed to the branched chain structure of nano- $\mathrm{CaCO}_{3}$ and active groups on the surface of nano- $\mathrm{CaCO}_{3}$.
\end{abstract}

Key Words: Polydimethylsiloxane, Nano-calcium carbonate, Interaction, Stress-softening.

Key Words: Polydimethylsiloxane, Nano-calcium carbonate, Interaction, Stress-softening.

\section{INTRODUCTION}

Room-temperature vulcanizable silicone rubbers have been widely used for glazing sealing windows and doors for either residential or public buildings ${ }^{1-5}$. Most room-temperature vulcanizable silicone sealants are formulated from a silanol-terminated polydimethylsiloxane (PDMS) and a large excess of crosslinker. They are easily transformed into a three dimensional network when exposed to atmospheric moisture. Usually, the maximal tensile strength of unfilled room-temperature vulcanizable silicone rubber is very low (about 0.35 $\mathrm{MPa}$ ) and there does not have much applications. For this and other reasons, most applications require that room-temperature vulcanizable silicone rubber be reinforced by particulate fillers, such as silica and carbon black ${ }^{6-9}$. The addition of fillers usually leads to an increase in modulus, tensile strength and abrasion. The highly branched structure and active group on the surface of silica and carbon black are believed to be the reason of strong interaction between the polydimethylsiloxane and fillers, that results in the enhancement of mechanical properties.

Conventional micro-calcium carbonate has been long time used as mineral filler that extends and reduce the cost of the elastomers. However, a decrease of mechanical properties was usually reported ${ }^{10-12}$. With the development of nano-technology, calcium carbonate with nano-size has attracted more and more interests due to its raw materials abundance in nature, low cost compared with fumed silica, the presence of activity by treatment of the surface. In our previous work, the reinforcement of polydimethylsiloxane network by nano-calcium carbonate was investigated ${ }^{13-15}$. It has been found a simultaneous increase of tensile strength, modulus and elongation of polydimethylsiloxane with increasing of weight fraction of nano-calcium carbonate, which suggests that nano-calcium carbonate particles can be indeed used as reinforcing agents, just like silica or black carbon.

In this work, to better understanding the reinforcing mechanism involved in the nano- $\mathrm{CaCO}_{3}$ reinforced polydimethylsiloxane, we focused on the unique stress-softening and the interaction between rubber chains and the filler. The stress-softening was found for both unfilled and filled polydimethylsiloxane, but more serious in filled polydimethylsiloxane, particularly for sample with high filler content. A strong interaction was verified by swollen experiment, crosslinking density measurement, dynamic laser light scattering and IR experiment. The results show that the reason of the interaction can be attributed to the branched chain structure of nano- $\mathrm{CaCO}_{3}$, as proved by TEM and active group on the surface of nano- $\mathrm{CaCO}_{3}$, as proved by IR.

\section{EXPERIMENTAL}

In the work, the general chemical reactions involved in the formation of polydimethylsiloxane network are shown as follows: 


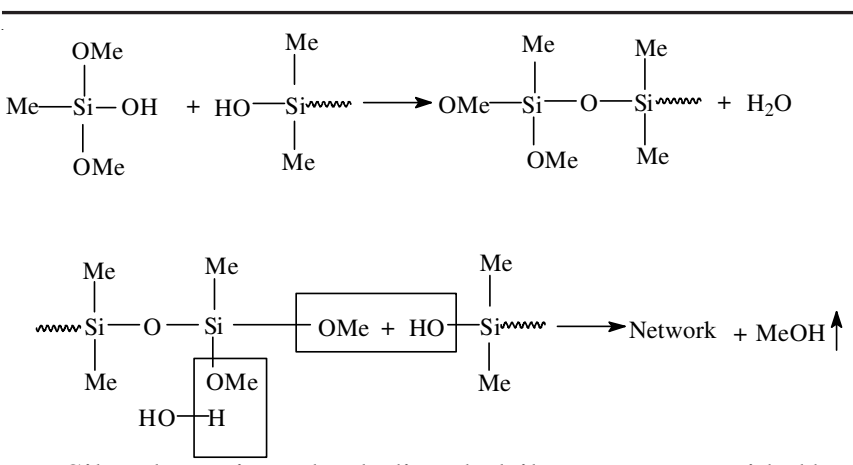

Silanol-terminated polydimethylsiloxane was provided by Xinghuo Chemical Factory and its viscosity was $3 \times 10^{4} \mathrm{~Pa}$.s. Methyltrimethoxysilane and the titanium-based catalysts were produced by Baiyun Chemical Ltd. Co. The nano-calcium carbonate was provided by Shiraishi Kogyo Kaisha, Ltd. The particle shape of this kind of nano- $\mathrm{CaCO}_{3}$ is cubic and the size of primacy is less than $100 \mathrm{~nm}$. The BET surface is about $27 \mathrm{~m}^{2} / \mathrm{g}$, which is much higher than that of normal microcalcium carbonates $\left(2.4-8.0 \mathrm{~m}^{2} / \mathrm{g}\right)^{16}$. The surface of the nanoparticle was mainly modified with stearic acid.

Samples preparation: Polydimethylsiloxane and nanocalcium carbonate were mixed in a laboratory-size two-roll mixer with vacuum pump for $2 \mathrm{~h}$. And then the samples were further grounded by three-roll mill to obtain good dispersion of filler in the matrix. About $2 \mathrm{~mm}$ thick of the films were produced after adding the crosslinker and catalysts. Dumb-bell test pieces were then cut out after the samples were vulcanized completely. Samples with various filler concentration from $20 \mathrm{phr}$ (per hundred rubbers) to $100 \mathrm{phr}$ and pure unfilled elastomers acting on control sample were prepared. It should be noted that here we use 100 rubber $(\mathrm{g})$ as a reference, instead of total percentage, because it is widely used in rubber industry.

Stress softening: Polydimethylsiloxane samples were first extended to a given strain (100\% or $200 \%)$, then released and next stretched again, at second extending and for strain values below the ones of the first stretching, the elastomers exhibit a reduced stress. Instron 4302 testing machine was used to measure the stress-strain curves and the cross-head speed was $50 \mathrm{~mm} / \mathrm{min}$. The measuring temperature was $20^{\circ} \mathrm{C}$.

Dynamic laser light scattering: The uncured polydimethylsiloxane filled by nano- $\mathrm{CaCO}_{3}$ were resolved by toluene fully and then the dispersion was clarified using $0.5 \mu \mathrm{m}$ Millipore filter and characterized by laser light scattering spectrometer (ALV/SP-125) equipped with a multi-tdigital time correlation (ALV 500E) and a solid -state laser (ADLAS DPY 425II, output $=50 \mathrm{nw}$ at $\lambda_{0}=532 \mathrm{~nm}$ ) as light source. The incident beam was vertically polarized with respect to the scattering plane. In dynamic laser light scattering, the intensitytime correlation function $\mathrm{G}(\mathrm{q}, \mathrm{t})$ in the self-beating mode can result in a line-width distribution $G(\Gamma)$. For a pure diffusive relaxation, $G(\Gamma)$ can be transferred into a transitional diffusion coefficient distribution G (D). Since $\left(\Gamma / q^{2}\right)_{c \rightarrow 0, q \rightarrow 0} \rightarrow D$, a hydrodynamic radius distribution $\mathrm{f}\left(\mathrm{R}_{\mathrm{n}}\right)$ via the Stokes-Einstein equation $R_{h}=\left(K_{B} T / 6 \pi \eta\right) D^{-1}$, where, $K_{B}, T$ and $\eta$ are the Boltzman constant, the absolute temperature and the solvent viscosity, respectively. All the laser light scattering measurements were performed at $25 \pm 1{ }^{\circ} \mathrm{C}$.
Cross-linking density: The equilibrium swelling of the crosslinked network was induced by exposure to toluene. Free chains were extracted from the vulcanized networks after washing until the equilibrium swelling was reached. $V_{r}$ can be defined as the fraction of volume of rubber swollen in equilibrium given by following equation ${ }^{17}$.

$$
\mathrm{V}_{\mathrm{r}}=\frac{1}{1+\frac{\rho_{\mathrm{p}}}{\rho_{\mathrm{s}}}\left(\frac{\mathrm{M}_{\mathrm{Qm}_{\mathrm{m}}}-\mathrm{M}_{\mathrm{G}}}{\mathrm{M}_{\mathrm{G}}}\right)\left(1+\phi_{\mathrm{Si}}\right)}
$$

where, $\mathrm{M}_{\mathrm{Q}_{\mathrm{m}}}$ is the weight of the swollen gel, including nano$\mathrm{CaCO}_{3} ; \mathrm{M}_{\mathrm{G}}$ denote the weight of nano- $\mathrm{CaCO}_{3}$ and crosslinked polymer measured after extracting free chains; $\rho_{\mathrm{p}}$ and $\rho_{\mathrm{s}}$ are the densities of polydimethylsiloxane and toluene respectively; $\phi_{\mathrm{Si}}$ is the weight ratio of filler. In order to distinguish the contribution from physical cross-linking and chemical crossinglinking, the similar experiments have been done but in an ammonia atmosphere as solvent, by which the physical crosslinking will be excluded.

Transmission electron microscope: The particle sizes of the nanoparticles were determined by a JEOL JEM-100 CXII transmission electron microscope (TEM). To prepare the nanoparticle sample for TEM examination, the $\mathrm{CaCO}_{3}$ nanoparticles were dispersed in ethanol in an ultrasonic bath for $10 \mathrm{~min}$.

IR: A Fourier transform infrared spectrometer (VECTOR22) was used to detect the absorption peaks of unfilled and filled samples. The samples were prepared using the $\mathrm{KBr}$ pellet technique.

\section{RESULTS AND DISCUSSION}

Softening by deformation: Stress softening was first reported in black-carbonate filled elastmor by Holt and Mullines ${ }^{18,19}$. Filled elastomers have usually shown the peculiar ability to dissipate an important part of mechanical energy during deformation ${ }^{20}$. It was found that when a filled elastomer is first extended to a given strain, then released and next stretched again, at second extending for strain values below the ones of the first stretching, the elastomer will exhibit a reduced tensile stress. This phenomenon is called stresssoftening, known as also Mullins effect. The following part will discuss the stress-softening dependence of nano-calcium carbonate content. In the previous work ${ }^{13}$, it has been mentioned that the incorporation of nano- $\mathrm{CaCO}_{3}$ particles in polydimethylsiloxane results in an increase of the modulus and the tensile properties of the materials, such as the stress and elongation at rupture, but also an increased stresssoftening.

Fig. 1 shows the typical cyclic stress-strain curves of the unfilled and filled polydimethylsiloxane networks at room temperature. Testing was performed in running from zero stress to appointed elongation and back to zero stress. After the three strain cycles, these samples were carried out the fourth strain cycles again when they have been laid aside at room temperature for $24 \mathrm{~h}$ for molecular relaxation. From the figures, the third stress-strain cycle curve is seen very close to the second one, thus can be considered as the equilibrium state or stable state. One sees the stress-softening both in unfilled and filled 
polydimethylsiloxane networks. However, compared with the unfilled one, the filled polydimethylsiloxane networks exhibit a much larger stress softening, in good agreement with that obtained by Mullins and later Harwood, et al. in black carbonate filled system ${ }^{21,22}$. The degree of Mullin effect can be described as the following equation:

$$
\mathrm{D}_{\mathrm{m}}=\left[\left(\mathrm{W}_{1}(\varepsilon)+\mathrm{W}_{\text {stable }}(\varepsilon)\right] / \mathrm{W} 1(\varepsilon)\right.
$$

where, $\mathrm{W}_{1}(\varepsilon)$ and $\mathrm{W}_{\text {stable }}(\varepsilon)$ are the area under the first extending curve and the stable extending (the third cycle) curve at a given straine, respectively. Table- 1 lists the $\mathrm{D}_{\mathrm{m}}$ of samples of different filler content at $100 \%$ strain and $200 \%$ strain.
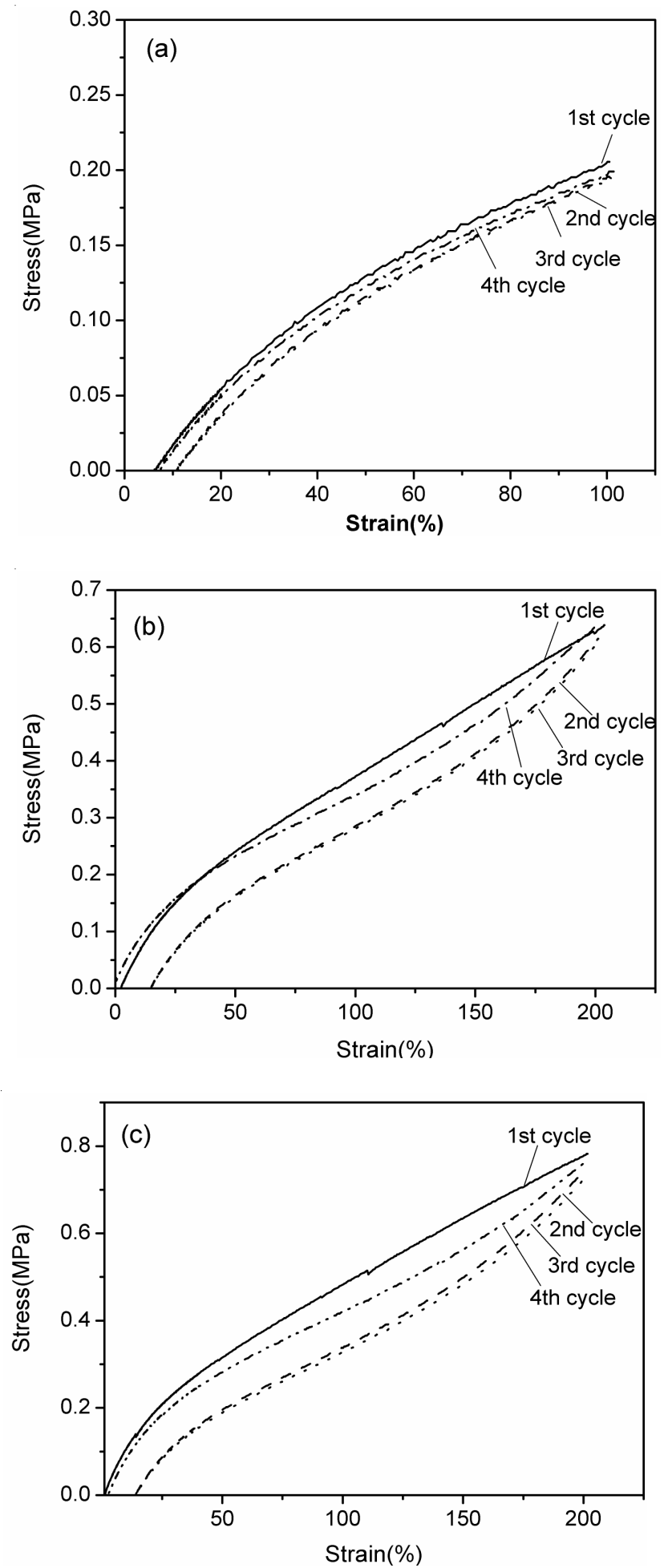
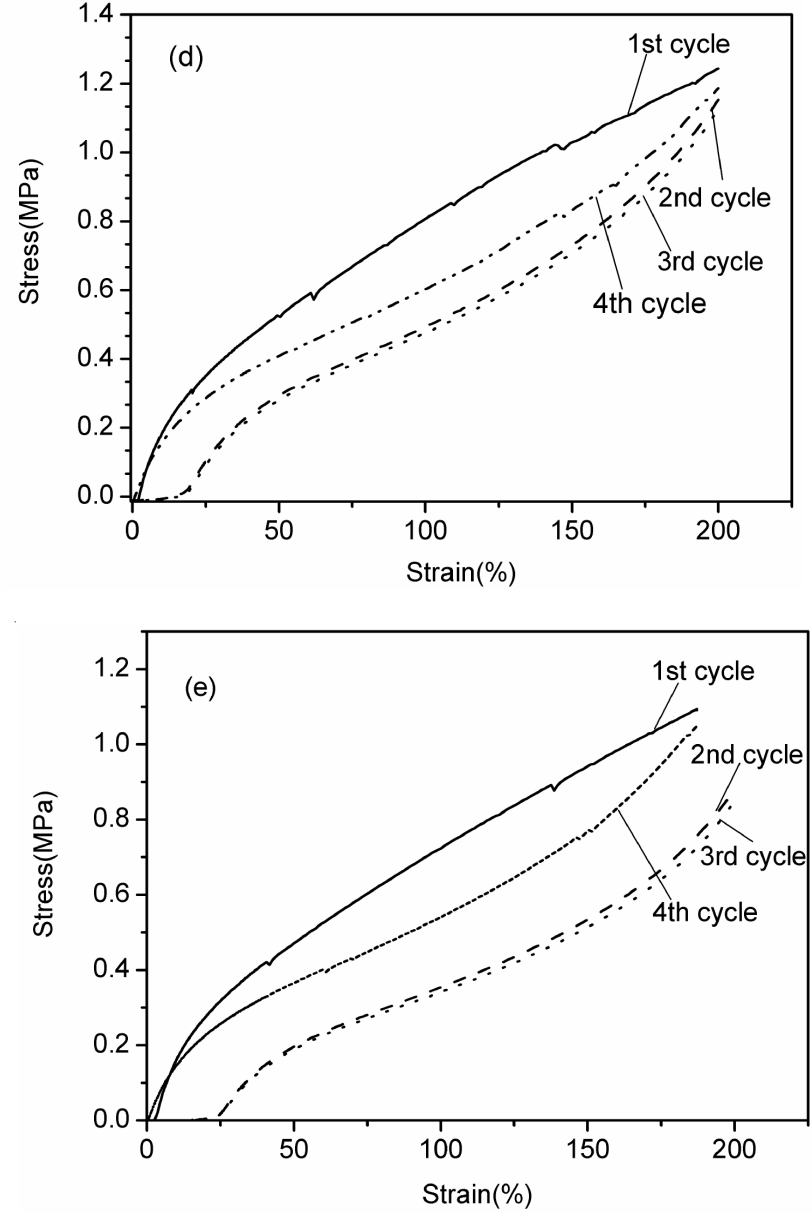

Fig. 1. Stress-strain curves of the elastomers with different filler contents: (a) pure elastomer; (b) $20 \mathrm{phr}$ filled elastomer; (c) $40 \mathrm{phr}$ filled elastomer; (d) $60 \mathrm{phr}$ filled elastomer; (e) $80 \mathrm{phr}$ filled elastomer

TABLE-1

DEGREE OF MULLINS EFFECT $\left(\mathrm{D}_{\mathrm{m}}\right)$ OF DIFFERENT FILLER CONTENT AT $100 \%$ STRAIN AND $200 \%$ STRAIN

\begin{tabular}{ccc}
\hline Filler content $(\mathrm{phr})$ & $\mathrm{D}_{\mathrm{m}} \%($ Strain $=100 \%)$ & $\mathrm{D}_{\mathrm{m}} \%($ Strain = 200\%) \\
\hline 0 & 9.79 & - \\
20 & 12.24 & 24.60 \\
40 & 12.68 & 29.36 \\
60 & 14.86 & 35.79 \\
80 & 21.63 & 43.43 \\
\hline
\end{tabular}

It is revealed that the degree of stress-softening increases as increasing of the weight fraction of filler, particularly at $200 \%$ strain. There exists two-step uptrend at the turning point $80 \mathrm{phr}$. For polydimethylsiloxane network with small filler content (less than $80 \mathrm{phr}$ ), the $\mathrm{D}_{\mathrm{m}}$ at the same strain increases slightly with addition of filler. For example, $\mathrm{D}_{\mathrm{m}}$ at $100 \%$ of the sample with $20 \mathrm{phr}$ filler is $12.24 \%$ and $14.86 \%$ for the one with $60 \mathrm{phr}$ filler. However, for polydimethylsiloxane network with $80 \mathrm{phr}$ filler, the $\mathrm{D}_{\mathrm{m}}$ at both $100 \%$ and $200 \%$ is $21.63 \%$ and $43.43 \%$, respectively, much larger than that of $60 \mathrm{phr}$ filler. After relaxation at room temperature for $24 \mathrm{~h}$, the same extending tests were done once again. The experimental data is listed in Table-2.

Degree of Mullen effect $\left(D_{m}\right)$ at $100 \%$ is seen to be quite small for all the unfilled and filled polydimethylsiloxane, indicating that the stress-softening can be largely recovered after molecular relaxation when the strain is small. However, 
one observes a relative big $\mathrm{D}_{\mathrm{m}}$ at $200 \%$, indicating that the stress-softening can not be easily recovered or need more time to go back to its original state, when the strain becomes large.

\begin{tabular}{|c|c|c|}
\hline \multicolumn{3}{|c|}{$\begin{array}{c}\text { TABLE-2 } \\
\text { DEGREE OF MULLINS EFFECT }\left(\mathrm{D}_{\mathrm{m}}\right) \text { OF DIFFERENT } \\
\text { FILLER CONTENT AT } 100 \% \text { STRAIN AND } \\
200 \% \text { STRAIN AFTER } 24 \mathrm{~h} \text { RECOVERY }\end{array}$} \\
\hline Filler content (phr) & $\mathrm{D}_{\mathrm{m}}($ Strain $=100 \%)$ & $\mathrm{D}_{\mathrm{m}}($ Strain $=200 \%)$ \\
\hline 0 & 3.72 & - \\
\hline 20 & 4.20 & 7.73 \\
\hline 40 & 3.57 & 10.11 \\
\hline 60 & 3.62 & 17.58 \\
\hline 80 & 3.68 & 27.78 \\
\hline
\end{tabular}

Kraus plot: Kraus equation is usually used to assess the interaction between the filler and polydimethylsiloxane $e^{23,24}$.

$$
\mathrm{V}_{\mathrm{r} 0} / \mathrm{V}_{\mathrm{rf}}=1-\mathrm{m} \phi(4-\phi)
$$

where $V_{\mathrm{r} 0}$ is the volume fraction of rubber network in the swollen phase for the unfilled rubber network and $V_{\text {rf }}$ is the volume fraction of rubber network in the swollen phase for the filled rubber network; $\mathrm{V}_{\mathrm{r} 0}$ and $\mathrm{V}_{\mathrm{rf}}$ were obtained by the equilibrium swelling experiment; $m$ is defined as the interaction intensity parameter; $\phi$ is defined as the volume fraction of fillers in the filled samples and determined by the following equation ${ }^{25}$.

$$
\phi=\omega_{\mathrm{f}} \rho_{\mathrm{m}} /\left[\omega_{\mathrm{f}}\left(\rho_{\mathrm{m}}-\rho_{\mathrm{f}}\right)+\rho_{\mathrm{f}}\right]
$$

where $\omega_{\mathrm{f}}$ is the weight fraction of fillers; $\rho_{\mathrm{m}}$ refers to the density of rubber and $\rho_{\mathrm{f}}$ is the filler density. In the plot of $\mathrm{V}_{\mathrm{r} 0} / \mathrm{V}_{\mathrm{rf}}$ versus $\phi(1-\phi)$ the slope of curve gives the value for the interaction intensity parameter (m). According to this theory, if a network is restricted by fillers through attachments to the fillers surfaces, then the ratio of $\mathrm{V}_{\mathrm{r} 0} / \mathrm{V}_{\mathrm{rf}}$ will decrease as the filler loading increases. In contrary, the ratio of $\mathrm{V}_{\mathrm{r} 0} / \mathrm{V}_{\mathrm{rf}}$ will increase for nonadhering filler. The linear decrease of swell with increasing volume fractions of filler is often used to classify the filler as reinforcing.

Fig. 2 shows that the ratio of $\mathrm{V}_{\mathrm{r} 0} / \mathrm{V}_{\mathrm{rf}}$ decreases with increasing filler concentration until the weight fraction of nano$\mathrm{CaCO}_{3}$ is 80 phr. At this point, the ratio stays constant with increasing filler concentration. Hence, the Kraus plot suggests the existence of adhesion between polydimethylsiloxane and nano- $\mathrm{CaCO}_{3}$.

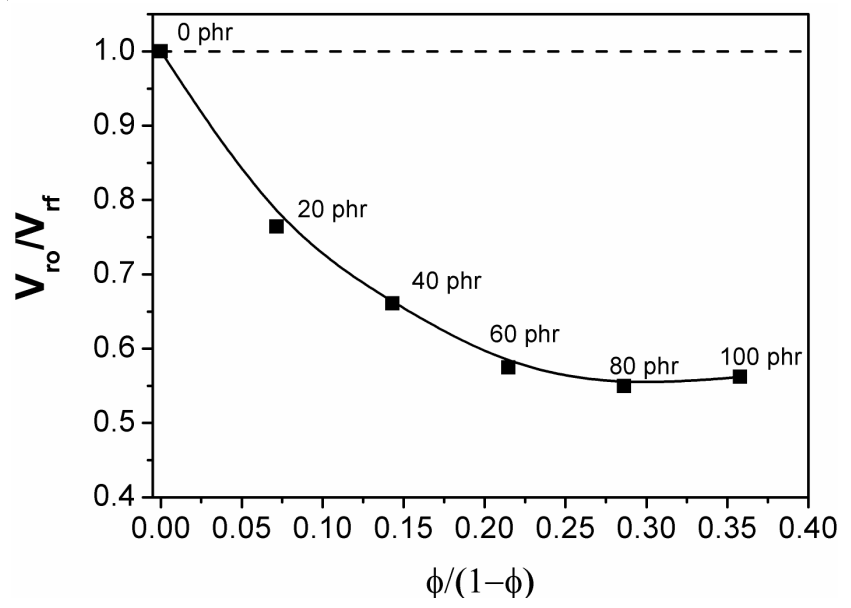

Fig. 2. Kraus plot of different concentration of nano- $\mathrm{CaCO}_{3}$ filled RTV silicone sealants
Crosslink density: The equilibrium swelling analysis of elastomer vulcanizates is well known to give an access to the number of effective network chains per unit volume of rubber. For a filled vulcanizate, it should reflect not only the effects of chemical junctions but also the density of polymer-filler attachments. The fraction of volume of rubber swollen in equilibrium, $\mathrm{V}_{\mathrm{r}}$, can be used to qualitatively estimate the crosslink density of the corresponding vulcanized compounds. The overall crosslink density $\left(\mathrm{V}_{\mathrm{r} 1}\right)$ can be obtained by swelling in pure toluene. Since these effective network chains are determined by the sum of chemical crosslink $\left(\mathrm{V}_{\mathrm{r} 2}\right)$ and the effective physical crosslink $\left(\mathrm{V}_{\mathrm{r} 3}\right)$. In order to gain some insight into the influence of polymer-filler attachments on the effective crosslink density, a method was developed to break the polymer-filler bonds by exposure to ammonia within the swelling environment used for measuring the crosslink density, chemical crosslink density $\left(\mathrm{V}_{\mathrm{r} 2}\right)^{26}$. The difference between overall crosslink $\left(\mathrm{V}_{\mathrm{r} 1}\right)$ and chemical crosslink density $\left(\mathrm{V}_{\mathrm{r} 2}\right)$ is the physical crosslink density $\left(\mathrm{V}_{\mathrm{r} 3}\right)$, which reflects the polymer-filler attachments. The result for our nano- $\mathrm{CaCO}_{3}$ filled polydimethylsiloxane is shown in Fig. 3 (Table-3).

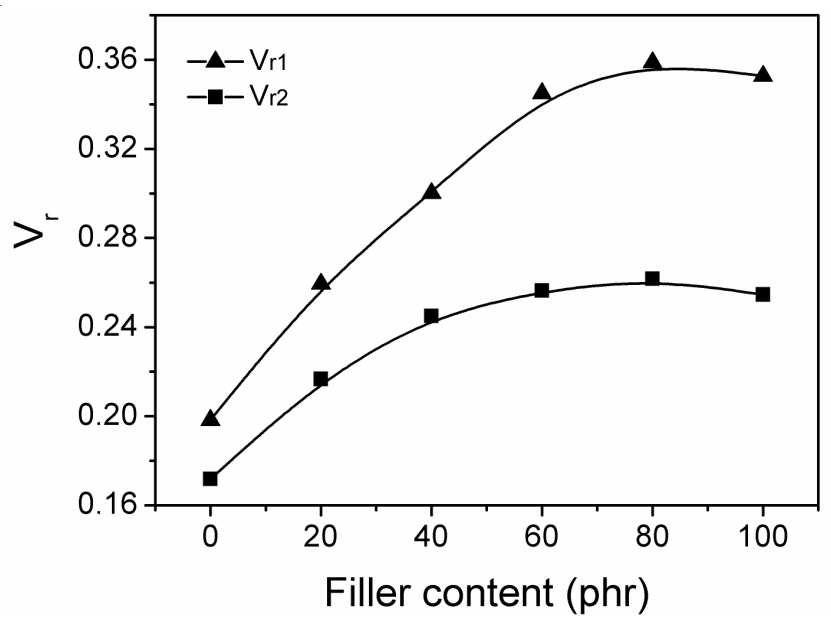

Fig. 3. Effect of nano- $\mathrm{CaCO}_{3}$ content on crosslink density of filled RTV silicone sealant

TABLE-3

VARIOUS CROSSLINK DENSITIES OF DIFFERENT FILLER CONCENTRATION RTV SEALANTS

\begin{tabular}{cccccc}
\hline $\begin{array}{c}\text { Filler content } \\
(\mathrm{phr})\end{array}$ & $\mathrm{V}_{\mathrm{r} 1}$ & $\mathrm{~V}_{\mathrm{r} 2}$ & $\mathrm{~V}_{\mathrm{r} 2} / \mathrm{V}_{\mathrm{r} 1}(\%)$ & $\mathrm{V}_{\mathrm{r} 3}$ & $\mathrm{~V}_{\mathrm{r} 3} / \mathrm{V}_{\mathrm{r} 1}(\%)$ \\
\hline 0 & 0.20 & 0.18 & 90.0 & 0.02 & 10.0 \\
20 & 0.26 & 0.22 & 84.6 & 0.04 & 15.4 \\
40 & 0.30 & 0.24 & 80.0 & 0.06 & 20.0 \\
60 & 0.32 & 0.25 & 78.1 & 0.07 & 21.9 \\
80 & 0.36 & 0.26 & 72.2 & 0.1 & 27.8 \\
100 & 0.35 & 0.25 & 71.4 & 0.1 & 28.6 \\
\hline
\end{tabular}

It can be seen that there exists a dramatic two-stage increasing trend of overall crosslink density $\left(\mathrm{V}_{\mathrm{r} 1}\right)$, chemical crosslink density $\left(\mathrm{V}_{\mathrm{r} 2}\right)$ and physical crosslink density $\left(\mathrm{V}_{\mathrm{r} 3}\right)$ with $80 \mathrm{phr}$ filler content as a turning points. From the data, the values of samples with lower than $80 \mathrm{phr}$ filler slightly increase with the increasing of weight fraction of filler. When the filler fraction is up to $80 \mathrm{phr}$, the crosslink densities especial physical crosslink densities $\left(\mathrm{V}_{\mathrm{r} 3}\right)$ shows a drastically increase. 
After the filler content reaches to $80 \mathrm{phr}$, the over crosslink density leaves off. The change of overall cross-linking density with increasing of filler content can be well used to explain the observed reinforcement of tensile properties reported in

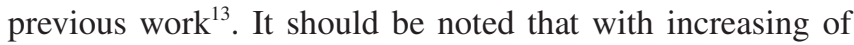
filler content, the contribution of chemical cross-linking decreases and physical cross-linking increases. Since the reactive sites result from the rupture of the filler aggregates, the number of reactive sites should increase with the degree of filler dispersion. Therefore, these new reactive sites should be capable of interacting with the polymer, taking part in siloxane rearrangment which results in an increase of the crosslinking density, especial the physical crosslink density, which can also be obtained by analyzing the ratios of $\left(\mathrm{V}_{\mathrm{r} 3} / \mathrm{V}_{\mathrm{r} 1}\right)$. At the same time, the increase of cross-linking density can improve the mechanical properties of nano- $\mathrm{CaCO}_{3}$ filled polydimethylsiloxane networks.

Laser light scattering: The interaction between nano$\mathrm{CaCO}_{3}$ particles and polydimethylsiloxane can be further investigated by measuring the hydrodynamic radius of polydimethylsiloxane in toluene solution via laser light scattering. Fig. 4 shows the hydrodynamic radius distribution of dispersion after filtering out of participates of nano- $\mathrm{CaCO}_{3}$ particles.

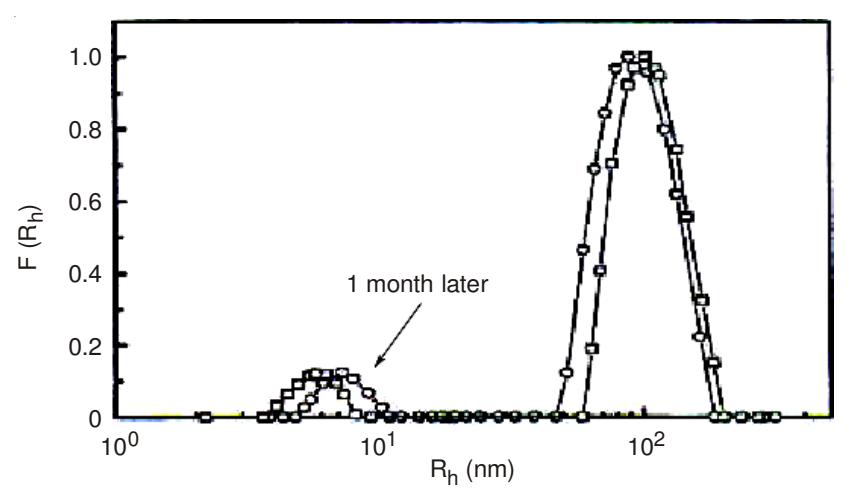

Fig. 4. Hydrodynamic radius of Nano- $\mathrm{CaCO}_{3}$ filled PDMS at different deposition time

It can be seen that the distribution are bimodal. The peak corresponding to $\left\langle\mathrm{R}_{\mathrm{h}}\right\rangle=-6 \mathrm{~nm}$ is obviously attributed to the polydimethylsiloxane chains. The other corresponding to $\left\langle\mathrm{R}_{\mathrm{h}}>\right.$ $=-102 \mathrm{~nm}$ suggests a new structure formed in the solution. Since the nano- $\mathrm{CaCO}_{3}$ particles will be completely precipitated in toluene without polydimethylsiloxane polymers, the hydrodynamic radius of $\left\langle\mathrm{R}_{\mathrm{h}}\right\rangle=-102 \mathrm{~nm}$ indicates a formation of a complex between nano- $\mathrm{CaCO}_{3}$ particles and polydimethylsiloxane, which results in a huge hydrodynamic radius in the solution. The same characterization was done when the dispersion laid aside at room temperature for a month. The curve exhibits the two peaks at the similar hydrodynamic radius, which reflects that the complex is quite stable due to the interaction between polydimethylsiloxane molecules and nano$\mathrm{CaCO}_{3}$.

In order to analyze the effect of grinding temperature on the interaction between polydimethylsiloxane and the filler, two filled polydimethylsiloxane samples with the same weight fraction but different grinding temperature were used. The grinding temperatures were at room temperature and at $120^{\circ} \mathrm{C}$ respectively. The results of laser light scattering are shown in Fig. 5.

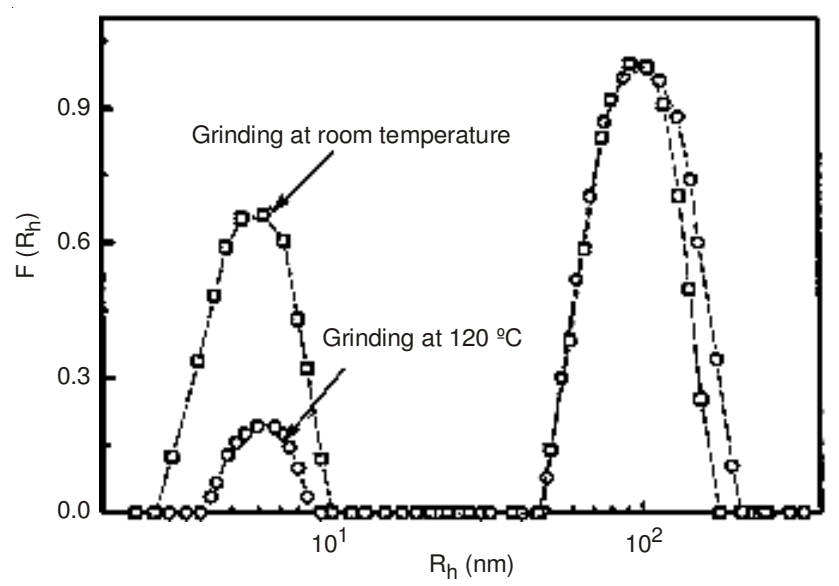

Fig. 5. Hydrodynamic radius of Nano- $\mathrm{CaCO}_{3}-1$ filled PDMS at different processing temperatures

As can be seen in the figure, two dispersions of samples exhibit two peaks in hydrodynamic radius curves. Although the peaks of two samples appear in the same hydrodynamic radius, the intensity of peak at $\left\langle\mathrm{R}_{\mathrm{h}}\right\rangle=-6 \mathrm{~nm}$ of the sample ground at room temperature is much higher than that of the sample ground at $120^{\circ} \mathrm{C}$. This result suggests that the higher the grinding temperature is, the more the complex forms thus the less of free polydimethylsiloxane chain. This could be understood that at high grinding temperature, polydimethylsiloxane molecules chains and nano- $\mathrm{CaCO}_{3}$ can be mixed to a high degree, thus results in an enhanced interaction between them.

TEM and IR: Now it is logical to ask the reason of strong interaction between nano- $\mathrm{CaCO}_{3}$ and polydimethylsiloxane. The highly branched structure and active group on the surface of silica and carbon black are believed to be the reason of strong interaction between the polydimethylsiloxane and the fillers in those systems. In our nano- $\mathrm{CaCO}_{3}$ filled polydimethylsiloxane, we also carried out the TEM and IR experiments to see the structure and active group on the surface of nano- $\mathrm{CaCO}_{3}$. The TEM result is shown in Fig. 6, one TEM photograph of silica is also included for comparison. Before TEM experiment, the fillers were dispersed by ultra-sonic in ethanol. One also observes the aggregates and branched chain structure of nano- $\mathrm{CaCO}_{3}$ particles, even if the size of primacy particles is less than $100 \mathrm{~nm}$. However, compared with silica, nano- $\mathrm{CaCO}_{3}$ shows a less branched chain structure.

Fig. 6 shows the aggregates and branched chain structure of nano- $\mathrm{CaCO}_{3}$ particles, even the size of primacy particles is less than $100 \mathrm{~nm}$. Compared with silica, nano- $\mathrm{CaCO}_{3}$ shows a less branched chain structure.

The IR spectra of pure polydimethylsiloxane, $20 \mathrm{phr}$ nano$\mathrm{CaCO}_{3}$ filled polydimethylsiloxane (uncured), $80 \mathrm{phr}$ nano$\mathrm{CaCO}_{3}$ filled polydimethylsiloxane (uncured) and pure nano$\mathrm{CaCO}_{3}$ are shown in Fig. 7.

In IR spectra of polydimethylsiloxane, a characteristic peak at $3700 \mathrm{~cm}^{-1}$ is due to the $\mathrm{O}-\mathrm{H}$ bond stretching vibration in the silanol of terminal group of polydimethylsiloxane. 
However, the intensity of absorbance at $3700 \mathrm{~cm}^{-1}$ lessens in the IR spectra of 20 phr nano- $\mathrm{CaCO}_{3}$ filled polydimethylsiloxane. When the weight fraction of filler adds to $80 \mathrm{phr}$, the peak at $3700 \mathrm{~cm}^{-1}$ in the IR spectra disappears. IR result suggests that the silanol of polydimethylsiloxane may be interacted with the surface agent of nano- $\mathrm{CaCO}_{3}$. The schematic mode of interaction between nano- $\mathrm{CaCO}_{3}$ is shown in shown in Fig. 8 .

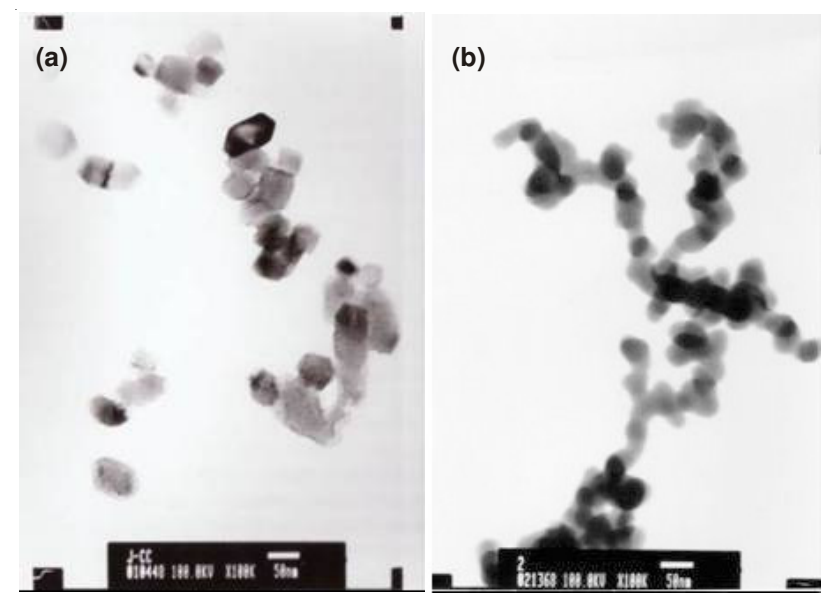

Fig. 6. TEM micrographs of fillers (a) nano-calcium carbonate, (b) fumed silica

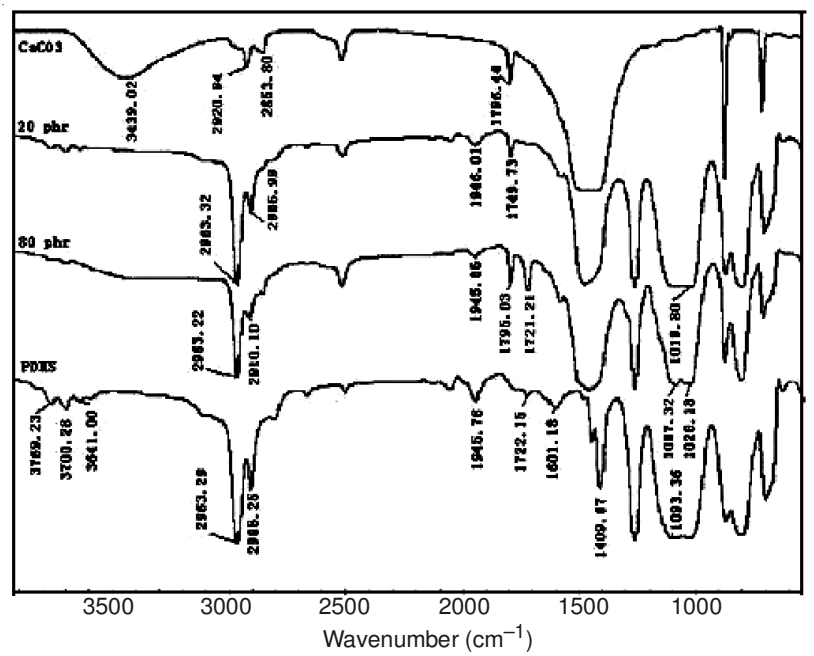

Fig. 7. IR spectra of PDMS, $20 \mathrm{phr}, 80 \mathrm{phr}$ nano- $\mathrm{CaCO}_{3}$ filled $\mathrm{PDMS}$ and $\mathrm{CaCO}_{3}$

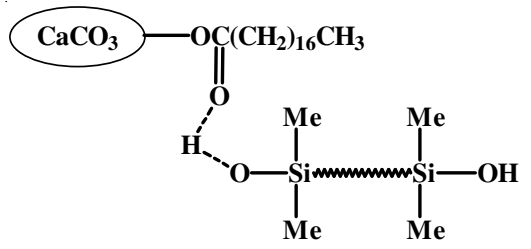

Fig. 8. Model of interaction between nano- $\mathrm{CaCO}_{3}$ and $\mathrm{PDMS}$

\section{Conclusion}

The incorporation of nano- $\mathrm{CaCO}_{3}$ particles in polydimethylsiloxane results in an increase of the modulus and the tensile properties of the materials, such as the stress and elongation at rupture, but also an increased stress-softening. The stresssoftening was found for both unfilled and filled polydimethylsiloxane, but more serious in filled polydimethylsiloxane, particularly for samples with high filler content. The strong interaction exists between polydimethylsiloxane and nanocalcium carbonate and this can be verified by swelling experiment, cross-linking density measurement, dynamic laser light scattering and IR experiment. The reason of the interaction can be attributed to the branched chain structure of nano- $\mathrm{CaCO}_{3}$ and active group on the surface of nano- $\mathrm{CaCO}_{3}$.

\section{ACKNOWLEDGEMENTS}

The authors express their sincere thanks to Key Science and Technology Financing Projects of Ministry of Education of China(No. 210193), The Key Project of Sichuan Provincial Education Department (No. 12ZA159) Applied Basic Research Programs of Science and Technology Commission Foundation of Sichuan Province (No. 2006J13-055) \& (No. 2009JY0141) and the Basic Research Project of Science and Technology Department of Sichuan Province of China and the Open Research Fund of Key Laboratory of Advanced Technologies of Materials (Ministry of Education) of Southwest Jiaotong University.

\section{REFERENCES}

1. M.J. Scheffler and J.D. Connelly, ASTM Spec. Tech. Publ., 5, 299 (1996).

2. G. Maquire, Mater. Eng., 108, 29 (1991).

3. W.E. Dennis, D.A. Sierawski, D.N. Ingerbrigstoon, Rubber World, 193, 26 (1985).

4. S.H. Kim, E.A. Cherney and R.H. Hackam, IEEE Trans. Elect. Insul., 27, 1065 (1992).

5. B. Yactine, B. Boutevin and F. Ganachaud, Polym. Adv. Technol., 20, 1 (2009).

6. J.P. Cohen Addad, Polymer, 33, 2762 (1992).

7. S. Wolff, Rub. Chem. Techn., 69, 325 (1996).

8. J.L. Leblanc, J. Appl. Polym. Sci., 78, 1541 (2000).

9. M.J. Wang and S. Wolff, Rub. Chem. Technol., 66, 178 (1993).

10. R.M. McGenity, J.J. Hooper and C.D. Paynter, Polymer, 33, 5215 (1992).

11. H.L. Pan, Adv. Chem. Eng., 2, 40 (1996).

12. V. Khunova, J. Hust, I. Janigova and V. Smatko, Polym.Test., 18, 501 (1990).

13. Y. Peng, R.-N. Du, Q. Fu and Y.-L. Wang, Chin. J. Polym. Sci., 23, 411 (2005).

14. X.-M. Xu, Y.H. Song, Q. Zheng and G.H. Hu, J. Appl. Polym. Sci., 103, 2027 (2007)

15. Y.B. Zhou, S.F. Wang, Y. Zhang, Y.X. Zhang, X.H. Jiang and D.F. Yi, J. Appl. Polym. Sci., 101, 3395 (2006).

16. S.Y. Wu, W.S. Ma and P.F. Ye, China Elastomerics, 13, 57 (2003).

17. J.P. Cohen Addad and H. Montes, Macromolecules, 30, 3678 (1997).

18. L. Mullins and N.R. Tobin, Rubb. Chem. Technol., 30, 555 (1957).

19. A.F. Blanchard and D. Parkinson, Ind. Eng. Chem., 44, 799 (1952).

20. F. Clement, A. Lapra, L. Bokobza, L. Monnerie and P. Menez, Polymer, 42, 6259 (2001).

21. L. Mullins, J. Rubber Res., 16, 275 (1947).

22. J.A.C. Harwood, A.R. Payne and R.E. Whittaker, J. Macro. Sci.-Phys., 5, 473 (1971).

23. G. Kraus, J. Appl. Polym. Sci., 7, 861 (1963).

24. Q. Deng, J.R. Hahn, J. Stasser, J.D. Preston and G.T. Burns, Rubb. Chem. Technol., 73, 647 (2000).

25. Q. Fu and G.H. Wang, J. Appl. Polym. Sci., 49, 673 (1993).

26. K.E. Polmanteer and C.W. Lentz, Rubb. Chem. Technol., 48, 795 (1975). 